\title{
A Revisit of Internet of Things Technologies for Monitoring and Control Strategies in Smart Agriculture
}

\author{
Amjad Rehman ${ }^{1, *(\mathbb{D})}$, Tanzila Saba ${ }^{1, *(\mathbb{D})}$, Muhammad Kashif ${ }^{2}$, Suliman Mohamed Fati ${ }^{1}{ }^{(\mathbb{D}}$, Saeed Ali Bahaj ${ }^{3}$ \\ and Huma Chaudhry ${ }^{4}$ \\ 1 Artificial Intelligence \& Data Analytics Lab., CCIS Prince Sultan University, Riyadh 11586, Saudi Arabia; \\ smfati@yahoo.com \\ 2 Department of Computer Science \& Software Engineering, International Islamic University, \\ Islamabad 44000, Pakistan; drkashif491@gmail.com \\ 3 MIS Department College of Business Administration, Prince Sattam Bin Abdulaziz University, \\ Alkharj 11942, Saudi Arabia; s.bahaj@psau.edu.sa \\ 4 Melbourne Institute of Technology, Melbourne, VIC 3000, Australia; huma.bicse@gmail.com \\ * Correspondence: arkhan@psu.edu.sa (A.R.); tsaba@psu.edu.sa (T.S.)
}

Citation: Rehman, A.; Saba, T.; Kashif, M.; Fati, S.M.; Bahaj, S.A.;

Chaudhry, H. A Revisit of Internet of Things Technologies for Monitoring and Control Strategies in Smart Agriculture. Agronomy 2022, 12, 127. https://doi.org/10.3390/ agronomy12010127

Academic Editor: Paul Kwan

Received: 7 October 2021

Accepted: 11 November 2021

Published: 5 January 2022

Publisher's Note: MDPI stays neutral with regard to jurisdictional claims in published maps and institutional affiliations.

Copyright: (C) 2022 by the authors Licensee MDPI, Basel, Switzerland. This article is an open access article distributed under the terms and conditions of the Creative Commons Attribution (CC BY) license (https:// creativecommons.org/licenses/by/ $4.0 /)$.

\begin{abstract}
With the rise of new technologies, such as the Internet of Things, raising the productivity of agricultural and farming activities is critical to improving yields and cost-effectiveness. IoT, in particular, can improve the efficiency of agriculture and farming processes by eliminating human intervention through automation. The fast rise of Internet of Things (IoT)-based tools has changed nearly all life sectors, including business, agriculture, surveillance, etc. These radical developments are upending traditional agricultural practices and presenting new options in the face of various obstacles. IoT aids in collecting data that is useful in the farming sector, such as changes in climatic conditions, soil fertility, amount of water required for crops, irrigation, insect and pest detection, bug location disruption of creatures to the sphere, and horticulture. IoT enables farmers to effectively use technology to monitor their forms remotely round the clock. Several sensors, including distributed WSNs (wireless sensor networks), are utilized for agricultural inspection and control, which is very important due to their exact output and utilization. In addition, cameras are utilized to keep an eye on the field from afar. The goal of this research is to evaluate smart agriculture using IoT approaches in depth. The paper demonstrates IoT applications, benefits, current obstacles, and potential solutions in smart agriculture. This smart agricultural system aims to find existing techniques that may be used to boost crop yield and save time, such as water, pesticides, irrigation, crop, and fertilizer management.
\end{abstract}

Keywords: agriculture; land monitoring; control strategies; IoT; sensors; economic growth; water management and water resources

\section{Introduction}

The Internet of Things (IoT) is an interconnected network of computing devices, people with unique IDs, and the capacity to communicate via a network without human interaction. The Internet of Things (IoT) intends to connect the physical and virtual worlds by interacting and exchanging data via the internet. Linked industries, smart cities, smart homes, smart energy, connected vehicles, smart agriculture, connected buildings and campuses, health care, and logistics are all examples of IoT applications [1]. The increasing need for food, both in terms of quantity and quality, has required the development and modernization of the agricultural sector. The "Internet of Things" (IoT) is a promising set of technologies that may be used to provide a variety of agricultural modernization solutions. Scientific institutions, research institutes, and the agricultural sector are racing to provide more and more IoT solutions to agricultural business stakeholders, laying the foundation for a clear role when IoT becomes a mainstream technology [2]. The world's biodiversity is anticipated to support between 9.4 and 10.1 billion people by 2050, increasing the need for specialized food production zones, especially for harvesting and livestock. This means 
that by 2050, global food production will have to grow by $70 \%$ [3]. Crop production is increasingly crucial in agriculture, with commodities, such as cotton, wheat, gum, and others, playing significant roles in many nations' economies.

In 2019, the IoT market was 690 billion dollars and was projected to be 1256.1 billion dollars by 2025 with a $10.53 \%$ CAGR globally from 2020 to 2025 . Solutions are needed to assure timely and regular agricultural growth and yield due to the combined effects of a growing population, natural weather unpredictability, soil degradation, and climate change. Farm management, animal monitoring, irrigation control, greenhouse environmental control, autonomous agricultural machinery, and drones are examples of IoT applications in agriculture, all of which contribute to agrarian automation. It also demands contributing to agricultural food production's long-term viability. Land appraisal, crop protection, and crop yield projection, according to these needs, are essential to world food production [4]. Farmers, for example, can manage field environments in real-time and more effortlessly regulate fields using wireless sensors and mobile networks. Farmers may also utilize IoT technology to capture essential data, subsequently creating yield maps that enable precision agriculture to produce low-cost high-quality crops [5]. Figure 1 depicts the smart precision agriculture cycle.

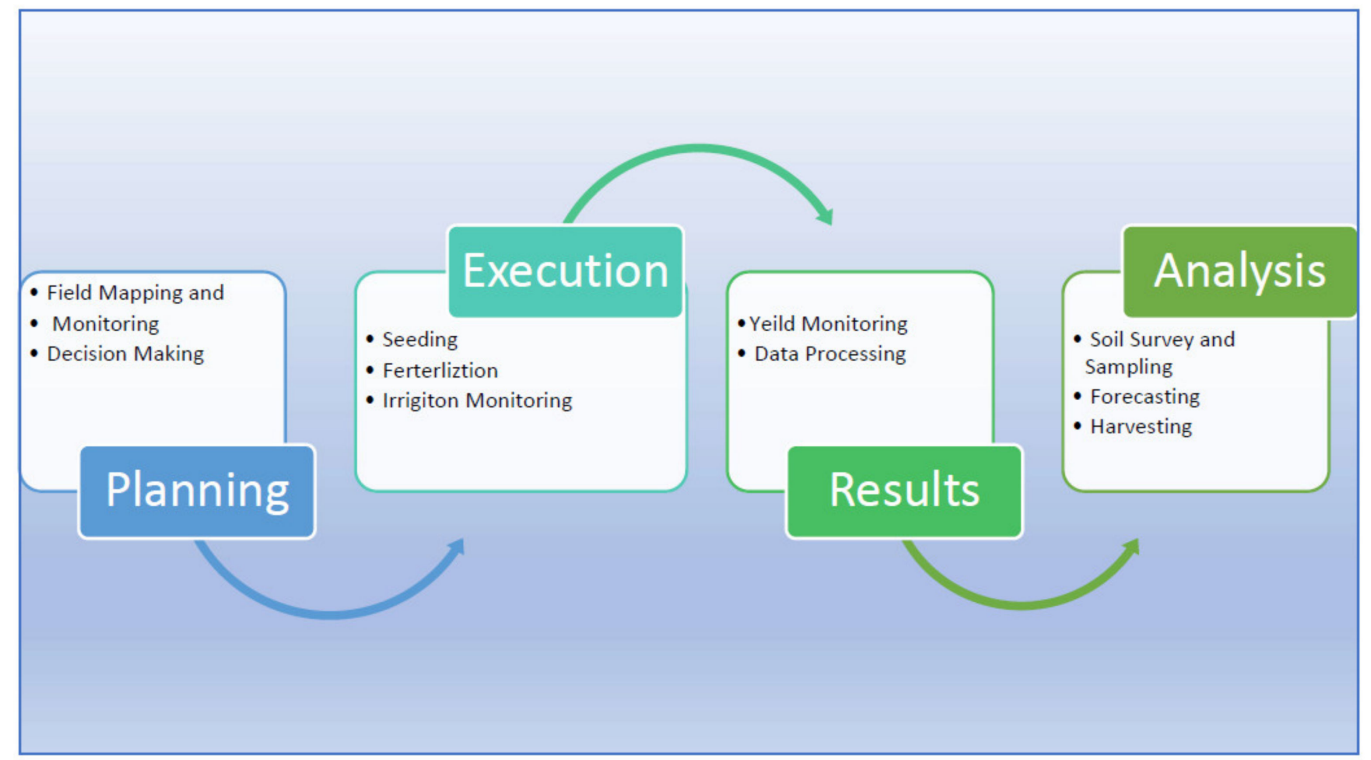

Figure 1. Smart precision agriculture cycle.

Smart agriculture is becoming increasingly important to farmers in the modern day, and it will become even more critical in the future to ensure proper field expansion and crop output. Unfortunately, traditional farming methods are not up to the task of meeting rising demand. As a result, the ground stays barren and devoid of fertility due to poor utilization of nutrients, water management, light, fertilizers, and pesticides. Crop diseases, water shortage, irrigation, and pesticide control monitoring are only some of the challenges that different IoT automation and control systems can efficiently address [6]. This is why contemporary agriculture employs smart equipment and tools from sowing through crop harvesting, storage, and transportation. The operation is smart and cost-effective due to its accurate monitoring capabilities and fast reporting using a range of sensors. Autonomous drones, harvesters, tractors, satellites, and robots are now complementing agricultural equipment. Sensors may be instantly placed and begin collecting data, which is then immediately available for further analysis over the internet. By enabling reliable data gathering at each place, sensor technology allows crop and site-specific agriculture [7]. Using advanced control methods to automate agricultural activities has increased crop production while also improving soil fertility.

The following are the significant contributions made by this study: 
- The world's expectations of the agriculture industry, based on existing IoT approaches for providing solutions and new applications and technology.

- Identification of numerous application fields, as well as a summary of the most recent state-of-the-art literature on IoT technology.

- The Internet of Things' task is to address these constraints and other challenges, such as resource scarcity and precise usage, climate change, etc.

The rest of the paper is laid out in the following manner. Section 2 delves into the details of smart agricultural applications based on IoT technologies. Section 3 discusses the many types of equipment and technology available. Section 4 identifies unsolved problems and potential remedies. Finally, Section 5 concludes the research.

\section{Major Applications of Smart Agriculture}

Precision farming, animal monitoring, and greenhouse monitoring are a few agricultural businesses utilizing the Internet of Things. Every element of traditional farming operation may be substantially improved by combining cutting-edge sensors and Internet of Things technology. At the moment, the Internet of Things' (IoT's) and wireless sensors' harmonious incorporation into smart agriculture can catapult agriculture to formerly inconceivable heights. Appropriateness of land, pest monitoring and control, irrigation, and yield optimization are just a few of the conventional agricultural issues that IoT may assist in resolving through the implementation of smart agriculture approaches [7]. Figure 2 illustrates the comprehensive paradigm of smart agricultural monitoring system applications, facilities, and sensors. Agriculture applications are classified as IoT agricultural apps, smartphone-based agricultural apps, and sensor-based agricultural apps. Wireless sensor networks (WSNs) have recently been used to enable IoT applications for smart agriculture, including irrigation sensor networks, frost event prediction, precision agriculture and soil farming, smart farming, and unsighted object recognition, among others [8]. Significant instances of how new technology assists in the general improvement of efficiency at various stages are included here.

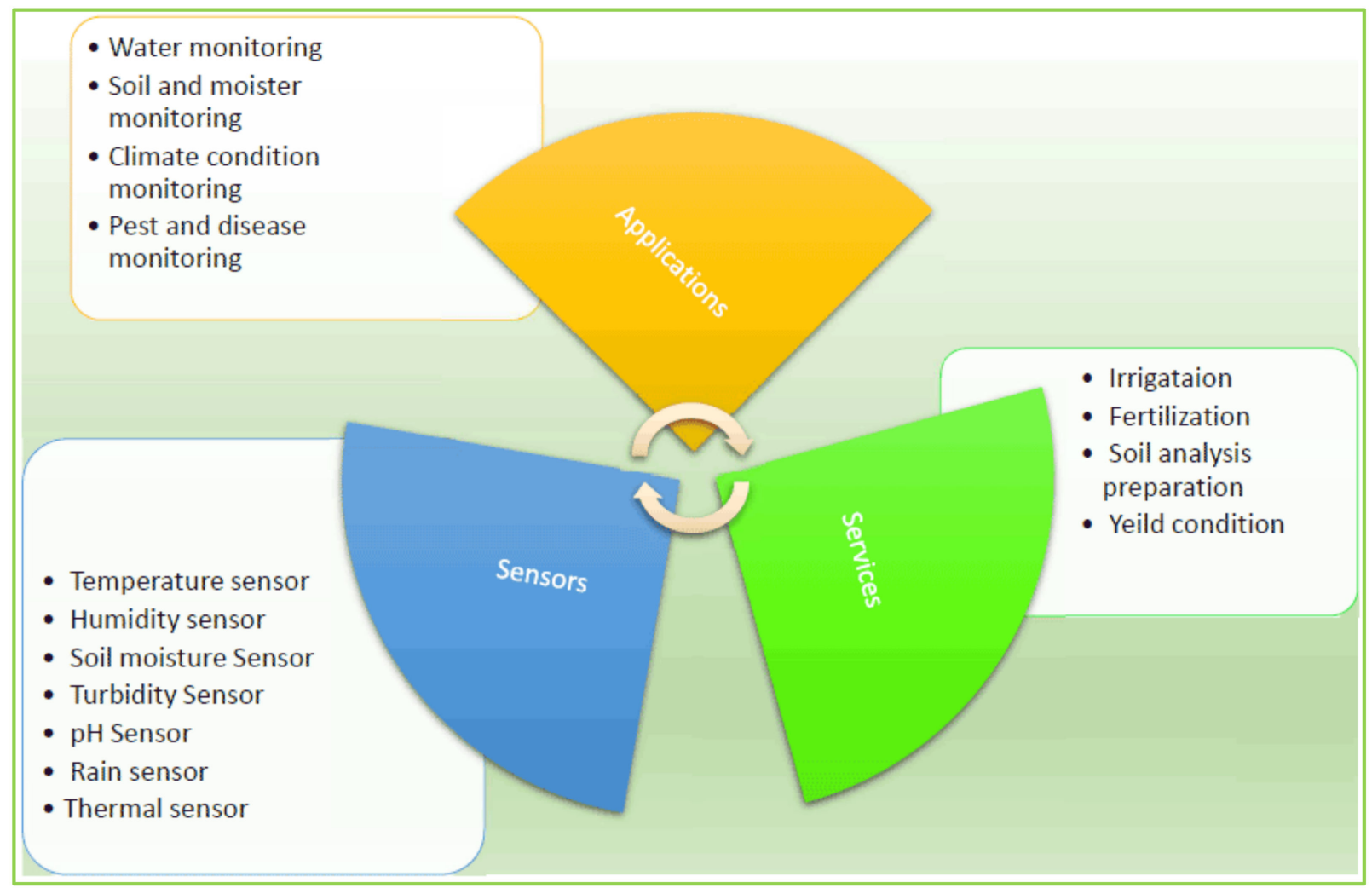

Figure 2. General paradigm of smart agriculture. 


\subsection{Monitoring of Soil Moisture and Water Levels}

Soil monitoring has developed into one of the most challenging agricultural areas, both for manufacturers and farmers. Numerous environmental issues associated with soil monitoring affect agricultural yield. When these sorts of obstacles are correctly identified, farming patterns and methods become readily understandable. The soil's moisture content, wetness, fertilizer application, and temperature trends are all being monitored. Soil's moisture environment management system uses soil humidity and moisture sensors. By proposing an appropriate fertilizer approach, the results of a soil monitoring test report assist farmers in increasing crop yield [9]. The sensor can read both analog and digital outputs. The judgment is made based on data collected from sensors and compared to predefined threshold levels. The soil moisture sensor is used to regulate the irrigation system's automatic operation. When the moisture level goes below the threshold value, the water pump is triggered [10].

Soil mapping enables you to sow many crop types in the same field, allowing you to match better soil characteristics, such as seed compatibility, sowing timing, and even planting depth, as certain crops are deeply rooted while others are not. Additionally, growing many crops concurrently may result in more prudent agricultural practices, such as resource conservation. The system is composed of a distributed network of soil moisture and temperature sensors located in the root zone of the plant, as well as rain sensors located in various zones. The microcontroller collects and transmits all sensor data and information. In addition, a temperature and soil moisture threshold algorithm will be devised and implemented in a microcontroller-based gateway to regulate the amount of water given to the fields. Finally, the user is provided with control via an IoT module based on rain sensor data to interrupt or restart water flow as needed [11].

If the field contains an adequate amount of water, no water will be pumped into it. However, when the soil's water moisture content falls below a predetermined level, water is pumped into the field until the desired moisture content is attained. The DHT11 sensor monitors the field's temperature and humidity. In addition, a PIR motion sensor detects when an intruder (human or animal) enters the area. Consequently, sensor values are continually monitored and displayed on the farmer's mobile device through a GSM sim900A module, which includes a sim card with a $3 \mathrm{G}$ data pack and adds IoT capabilities to the system [12].

\subsection{System of Irrigation Monitoring}

Numerous studies have been conducted on a smart irrigation system. Food production technology must significantly improve to keep up with the growing demand for food. Numerous experts have worked diligently to create an alternative to irrigated farming. These efforts, however, have not yet resulted in a feasible solution to the irrigation system's present problems. At the moment, crop irrigation is carried out manually and by established customary practices. When crops are given less water, they grow slower and absorb less calcium. Frequent irrigation kills roots and wastes water. As a result, accurate irrigation of crops becomes a considerable difficulty [13]. A smart irrigation management and monitoring approach is developed to enable autonomous delivery of sufficient water from a tank to field crops. Automatic sensor systems are cost-effective, offered for determining whether plants require watering based on information gathered from monitoring and regulating the soil water levels to minimize dryness or overflow [14].

Kamaruddin et al., 2019 [15] developed an Internet of Things (IoT)-based wireless sensor network (WSN) architecture that manually or automatically administers and monitors the irrigation system. The proposed method used NRF24L01 and Arduino tools as the communication network transceiver and CPU. The soil moisture sensor data will be sent to the base station via NRF24L01. Then, the sensor node's data will be sent to the cloud server through the base station. This project utilized Thingspeak as a cloud server to store all data in a database and connect it to an Android application. 


\subsection{Fertilizer Administration}

Akshaya et al., 2020 [16] proposed an IOT-based technique and upgraded the previous system, which predicted agricultural yields using backpropagation and a random forest algorithm. It recommends fertilizer application rates and exclusively monitors atmospheric data via a mobile network and pump on/off action. The suggested technique utilizes a segmented tank to collect NPK fertilizer and water. The user can select one of three modes (manual, auto, or smart). In manual mode, the user is provided with the fertilizer and water ratios for well-known plants and fertilizers. In auto mode, all required is to know the plant's name to select the appropriate fertilizer and water ratio. Finally, in smart mode, if the user cannot recognize the plant's name, fertilizer ratio, or water, the plant's name, fertilizer ratio, and water will be recommended automatically. The IoT module will continuously collect information on the temperature and soil moisture. The information collected will be stored in the IoT cloud. The mobile phone will inform you whenever the given data changes and the needed fertilizer ratio will be shown on the liquid crystal display.

\subsection{Crop Diseases and Pest Control}

Human operators frequently monitor insect pests via time-consuming and costly onsite inspections, which results in low spatial and temporal resolution. Remote monitoring has been possible due to advancements in remote sensing, electronics, and informatics. Monitoring costs and effectiveness can be optimized through the deployment of cameraequipped traps. With minimum human intervention, image analysis algorithms can locate and count insect pests captured in traps automatically.

Reddy et al., 2019 [17] created an IoT-based system for disease and insect pest management in agriculture and the prediction of plant climatic factors. The integrated sensors help in the measurement of soil and atmospheric moisture and humidity. These features help determine the environmental conditions in which the plant flourishes and the plants illnesses. It detects disease on the field and sprays prescribed insecticides. Web cameras take images that are then preprocessed to include RGB to grayscale conversion, defect detection, image scaling, image enhancement, and edge detection. SVM is utilized to categorize characteristics generated from Citrus Canker diseases, such as energy, kurtosis, skewness, and entropy (damaged Lemon crop). The Arm7 microcontroller is used for hardware, power, sensors, and motor driver control. Once the illness is identified, the program will propose fertilizers and transmit the results to an LCD and the recommended fertilizers. By pump, the fertilizers will be sprayed on the diseased leaves. This study was confined to the lemon plant to demonstrate that the same method may be used for various crops with favorable outcomes in the future.

A solution is presented for forecasting and detecting grape disease using the CNN approach and real-time gathered data on environmental factors. First, the CNN technique is utilized to analyze the leaf images. Then, different layers of the CNN method are used to create the image. Finally, it is scaled to a specific resolution before data is sent into the CNN layers for training and testing. The suggested algorithm was evaluated on four diseases known to have a higher effect on grape production. The diseases include esca black measles, anthracnose, leaf blight, and black rot. This gadget not only detects but also forecasts illnesses based on historical weather data. On the other side, the readings from the humidity, temperature, and soil moisture sensors are transferred through Raspberry Pi to Microsoft's Azure Cloud. Following this, the sensor readings are used to anticipate the illness using a trained linear regression model. Based on the findings of the preceding detection and prediction stages, suggestions for appropriate fertilizers in the right quantities will be provided to minimize fertilizer misuse and cost savings [18].

To detect pests in rice during field production and avoid rice loss, the Internet of Things supported a model-based UAV with the Imagga cloud offered. The Internet of Things-based UAV was developed on AI mechanisms and the Python programming prototype to transmit rice disease images to the Imagga cloud and supply insect data. The Approach identifies the 
disease and insects by integrating the confidence ratings of the labels. The label identifies the objects in the images. To determine the pest, the tag with the greatest confidence results and more than or equal to the threshold is chosen equal to the target label. If pests are discovered in the rice, statistics will be transferred to the field owner directly to take preventative actions. The suggested method is capable of detecting all pests that influence rice production. On the other hand, this research attempted to minimize rice waste during production by conducting insect monitoring at regular intervals [19]. Table 1 summarizes many current smart agricultural applications.

Table 1. Selected applications based on smart agriculture.

\begin{tabular}{|c|c|c|}
\hline Ref. & App & Description \\
\hline$[7]$ & Soil Analysis & $\begin{array}{l}\text { Land management offers long-term promise based } \\
\text { on climate, geography, and reasonably stable soil } \\
\text { characteristics (like soil texture, depth, and } \\
\text { mineralogy). This application aids farmers in better } \\
\text { understanding the potential of their land and climate } \\
\text { variations alteration and extenuation measures. }\end{array}$ \\
\hline [9] & Farm Manager & $\begin{array}{l}\text { Farm Manager App helps the farmers to decide } \\
\text { which techniques should apply before planting } \\
\text { starts. This app views, organizes, and edits all } \\
\text { information about your field like yield, planting, and } \\
\text { spraying conditions without your mobile phone. }\end{array}$ \\
\hline [7] & Pest Management & $\begin{array}{c}\text { By collecting pest occurrence information from } \\
\text { farms, Village Tree provides smart pest control } \\
\text { solutions. In addition, it employs a crowdsourcing } \\
\text { strategy, sending images and location data to other } \\
\text { farmers who may be affected. }\end{array}$ \\
\hline \multirow[t]{2}{*}{ [9] } & Agrippa & $\begin{array}{l}\text { Farmer can generate electronics maps of field, keep a } \\
\text { history of growing crops in the field (e.g., planting, } \\
\text { fertilizing, harvesting, warehouses, gas station), and } \\
\text { track the location of objects in the field (e.g., soil } \\
\text { sampling for agrochemical laboratory) by eFarmer } \\
\text { Application. }\end{array}$ \\
\hline & Semios & $\begin{array}{l}\text { Covers network coverage, orchard pests, frost, } \\
\text { diseases, and irrigation. Event notifications are sent } \\
\text { out in real-time as part of the monitoring services. }\end{array}$ \\
\hline [7] & $\begin{array}{l}\text { Fertilizer } \\
\text { Management }\end{array}$ & $\begin{array}{l}\text { Eco Fert assists with fertilizer management so that it } \\
\text { may be used to its full potential. It determines the } \\
\text { optimal fertilizer mixture created to cover the } \\
\text { needed nutrient suspension and considers the } \\
\text { demands of diverse yields. In addition, it considers } \\
\text { the cost of fertilizer based on current market pricing. }\end{array}$ \\
\hline
\end{tabular}

\subsection{Yield Monitoring, Forecasting and Harvesting}

The AWS IoT platform has been proposed for crop prediction using temperature and rainfall monitoring. The Raspberry $\mathrm{Pi}$ is utilized as a gateway for remote monitoring in this study. Raspberry Pi can connect with sensors to operate applications, such as the DHT11 Temperature Sensor and Soil Moisture Sensor, which forecasts temperature and rainfall ranges. The gateway is integrated with Amazon Web Services' (AWS) IoT platform. MQTT is a messaging protocol that allows for various messages across distant connections [20].

The study reported establishing an autonomous greenhouse smart aquaponics management organized on temperature via the use of an Android-based monitoring and automatic correction system and a Raspberry Pi-based plant growth monitoring system. Real-time data is collected using the light intensity sensor and the ambient temperature and humidity sensors. Additionally, the $\mathrm{pH}$ and temperature of the recirculating water are monitored. Suppose the data acquired is beyond the threshold range. In this case, the 
system quickly engages the correction devices, which comprise a peristaltic buffer device, an aerator, an evaporative cooler, inlet and exhaust fans, and grow lights. The internet remote access function enables real-time data transmission and receipt through the android app amongst the smartphone and computer system. This study compared plant development in smart aquaponics to traditional agriculture based on soil systems employing image processing in two investigational operations. Following record collection, it was determined that the smart aquaponics system achieved greater output than conventional agriculture monitoring. As lettuce, mustard greens, and pak choi are produced in a smart aquaponics system vs. traditional soil-based farming, this study focused exclusively on lettuce, mustard greens, and pak choi [21].

A tree topology was used for the WSN-enabled agricultural monitoring system to improve performance. A cheap sensor node like a commercial sensor or a NodeMCU module transmits data to the control unit over Wi-Fi. Fertilizer, fertigation improvement, and agricultural operations are monitored by data processing and thresholding. The incorporation of cost-effective ICT technology with traditional crop management or weather monitoring and sensor data created the agronomic model. Minimal environmental impact from crop growing was achieved as a consequence of large fertilizer and water savings [22].

\subsection{Climate Conditions Monitoring}

In farming, the weather is extremely important. Incorrect climate knowledge can have an impact on crop quality and quantity. On the other hand, farmers may use IoT solutions to put sensors in the field, including humidity sensors, temperature sensors, rainfall sensors, and water level sensors, to collect real-time data from the environment. These sensors monitor the state of crops and the environment in which they grow. If a worrying environmental situation is discovered, it is either automatically corrected or a warning is sent to the farmer.

Greenhouses created an Internet of Things-based weather station to address the cost and accuracy issues. The TI CC2650 Sensor Tag and IBM Cloud Platform continuously monitor weather and abiotic factors, transfer the detected values to the cloud, and send e-mail notifications when values deviate. As a result, this study may be expanded to include the use of ML model-based classification training to categorize a plant's health as excellent, moderate, or terrible based on the average temperature, humidity, light intensity, and air pressure. This would help to clarify abstracts about a plant's health to a larger level and might aid in keeping the plants' health in good shape [23].

Ariffin et al. [24] used an autonomous temperature control system to address the drawbacks of traditional growing methods, which are expensive, have low yields, and need a lot of care. The suggested IoT-based architecture was evaluated in a real-world setting at the Bandar Puteri Centre of NASOM (National Autism Society of Malaysia). The ideal temperature for oyster mushrooms is between 20 and $30^{\circ} \mathrm{C}$, with a humidity level of 70 to $80 \%$. Two sensors were installed in the mushroom house's center and corner to detect temperature and moisture, then communicated to a remote monitoring station through a microcontroller unit for further action. The results of the six-day experiment revealed that an effective automatic monitoring system, which can regulate the farm's home while reducing resources and human labor, was developed. The mushroom home, IoT control box, and Web Client interface were all designed within the system. As a result, the mushroom house provided a regulated environment for mushroom growing as well as protection from pests and insects. The climate control system, which automates controlling the ideal environment for oyster mushroom production, was housed in the IoT control box.

\section{Major Equipment and Technologies}

Major equipment and IoT technologies are fully demonstrated in the next subsections, such as various sensors, agricultural drones, and harvesting robots. 


\subsection{Sensors}

The visual sensor, multispectral sensor, thermal sensor, lidar sensor, and hyperspectral sensor are only a few of the sensors utilized in IoT-based smart agriculture and drone technologies. Current IoT-based sensor applications in smart agriculture are presented in Table 2.

Table 2. IoT-based sensors in smart agriculture used to increase production.

\begin{tabular}{cc}
\hline Sensors & $\begin{array}{c}\text { Operations of Different Sensors } \\
\text { DHT11 Sensor: }\end{array}$ \\
\hline DHT11 sensor measures temperature and humidity \\
[12].
\end{tabular}

The turbidity sensor determines the quality of water by detecting its turbidity level. It detects suspended

Turbidity Sensor SKU SEN0189: particles in water using light by measuring the light transmittance and scattering rate, which vary the quantity of total suspended solids (TSS) in the water [25].

\begin{tabular}{cc}
\hline MH-Z14A: & $\begin{array}{c}\text { This is used to monitor the CO2 level at high } \\
\text { precision. }\end{array}$ \\
BH1750: & $\begin{array}{c}\text { This is used to monitor the light intensity level (as } \\
\text { photosynthesis is related to light intensity) and to } \\
\text { conduct experiments on the influence of light } \\
\text { intensity on the greenhouse environment's } \\
\text { temperature [26]. }\end{array}$ \\
Rain sensor: & $\begin{array}{c}\text { A rain sensor is a simple instrument for detecting } \\
\text { rain pressure. It may be used as a switch to } \\
\text { determine the strength of rainfall when a raindrop } \\
\text { falls through the rainy board [27,28]. }\end{array}$ \\
\hline Lidar sensor: & $\begin{array}{c}\text { The top camera sensor is an imaging range camera } \\
\text { that estimates the distance between the camera and } \\
\text { the subject at each point in the collected images [29]. }\end{array}$ \\
\hline
\end{tabular}

\subsection{Agricultural Drones}

UAVs can monitor the health of crops, apply pesticides, and take hyperspectral images in precision agriculture. Drones can scan a crop for issues in plants using visible and near-infrared light, and they can determine which plants reflect what quantities of green and NIR light. Photosynthetic activity diminishes when a plant is stressed. This data may be used to create numerous images that track plant changes and indicate their health. As a result, farmers can more accurately administer treatments after a disease has been identified. Drones are also utilized for surveillance, traffic monitoring, and weather monitoring in agriculture. Drone technology employs various sensors, including optical, multispectral, thermal, lidar, and hyperspectral sensors, which are briefly detailed in Section 3.1.

Crop management has benefited from the Internet of Things, remote sensing, and analytic data approaches. Pests may be identified, targeted, and managed to utilize remote 
sensing using UAVs. UAVs can fly in tough and harsh terrains to take high-resolution images that allow pests to be identified and controlled. Many crop security concerns may be solved using UAVs equipped with cameras, which are not possible with traditional pest management methods. UAVs have been used to automate insect damage in agricultural areas $[30,31]$.

An automated rotating device based on sun illumination angle perception keeps the solar panel perpendicular to the sun and increases solar energy harvesting rates. Based on spectrum analysis technology, Internet of Things approaches, including several wireless technologies, such as TVWS, ZigBee, and LoRa, are suggested to collect data and send it to a base station/gateway to assess the degree of damage caused by pests and diseases. In addition, a technique for maximizing wind force usage and to extend the time of flight for drones has been established to support drones in downwind by designing the flying path implementation. The study's scope is limited, with the goal of developing a long-standing insect and disease detection technique through extensive data gathering and analysis. The suggested model will be tested in real-world scenarios. For example, crop diseases and insects might be tracked in real-time and climatic changes could be analyzed [32]. The Internet of Things-based approach is illustrated for smart agriculture monitoring in Figure 3.

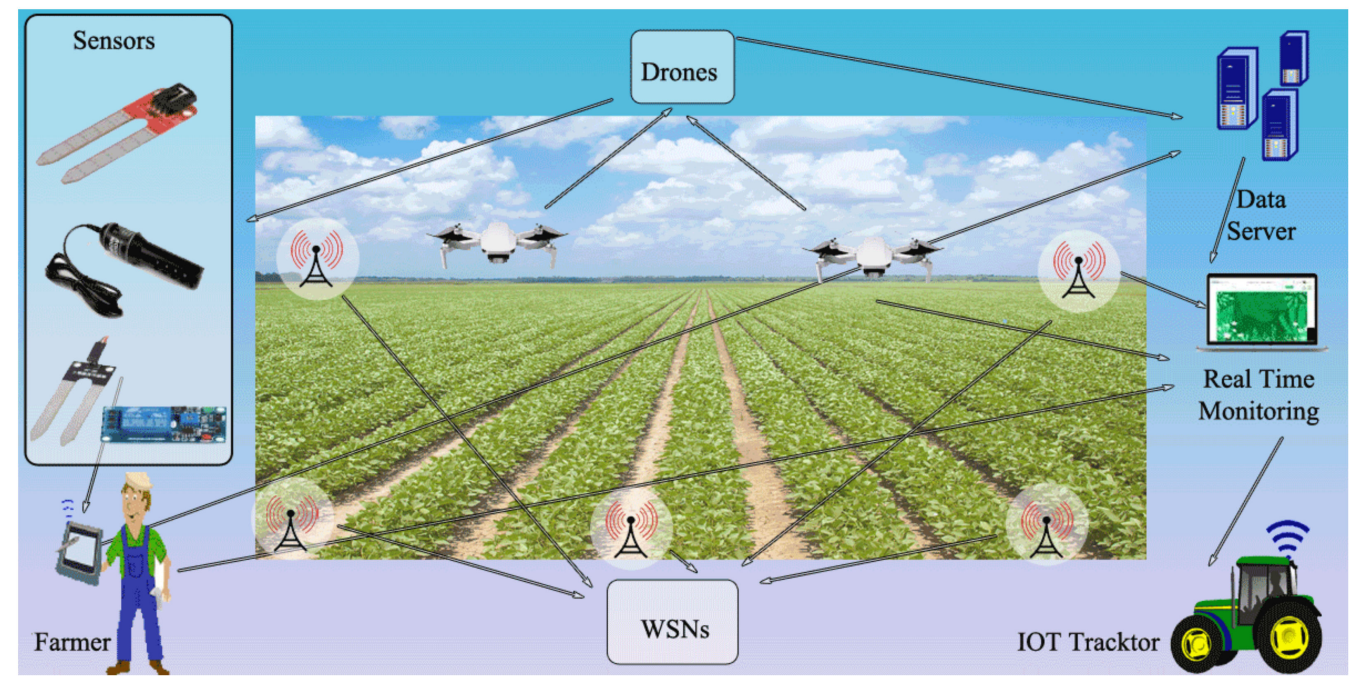

Figure 3. IOT-based smart agriculture monitoring system.

\subsection{Harvesting Robots}

Under specific climatic circumstances, a harvesting robot is intended to gather fruits autonomously. The advancement of vision-based harvesting robots' mechanism is yet in its early stages. Agricultural robotic systems, on the other hand, have comparable architecture. The system is comprised of an autonomous mobile platform, a lightweight mechanical arm with multiple degrees of freedom, an adaptable end effector for a power response system, a multi-sensor machine vision system, a smart decision and drive management system, and supplementary hardware and software [33]. Kang et al., 2020 [34] developed an intense neural network to assist robotic apple harvesting, which detects and grasps fruit in a real-time environment using a computer vision system. The proposed robotic harvesting system was implemented using a customized soft end-effector comprised of Intel i7-6700 CPU and NVIDIA GTX-1070 GPU and DELL-INSPIRATION main computer unit, Intel D-435 RGBD visualization camera, and UR5 Universal Robot (modern robotic manipulator). The proposed approach uses Mobile-DasNet, a computationally efficient lightweight one-stage instance segmentation network to conduct fruit recognition and instance segmentation on sensory input. An improved PointNet model was also developed to conduct fruit modeling and grip estimates from an RGB-D camera through the point clouds technique. The two qualities described above were utilized and integrated to 
develop and build a precise robotic system for autonomous fruit picking. The goal of the study was to improve the vision algorithm's performance, boost, and improvements.

Furthermore, the proposed soft end-effector robotic device may improve its grasping recognition proportion and effectiveness under various situations. Ogorodnikova and Ali [35] devised a technique for recognizing ripe tomatoes in a greenhouse setting using a machine vision system of a harvesting robot. To effectively execute the suggested image processing method for this purpose, RGB color images from a typical digital camera are required. In the second stage, RGB color images are converted to HSV, which is easier for extracting red tomato from the green backdrop in the image. Image segmentation, thresholding, and morphological operations separate a red tomato from a green background color photograph. The algorithm is built using Matlab methods and then evaluated to see if it produces favorable results. The process can be converted into fast-acting codes for the harvesting robot's controller since it is basic and short. The research is limited to moving the gripper to the proper place in tomato detection and developing efficient algorithms using 3D gripper models to transform the existing research system into industrial robots.

Only a few robotic devices that can successfully perform watering, planting, and weeding activities now exist. FaRo (Cultivating RObot), a new smart robot based on a CNC machine, has been presented for automatic crop farming deprived of human involvement in agriculture. What sets FaRo apart from other farming platforms is its capability to complete the entire farming cycle, from sowing to harvesting. In addition, the FaRo harvesting tool will be discussed and shown. FarmBot can only be used for a limited time, from sowing to harvesting, after which the robot's tool mount system will be exchanged for crop harvest. In this example, the robot assumes the role of a tomato collector. Both the FaRo harvesting robot and the unique kinematics of the continuum manipulator design were thoroughly discussed. Due to implementation problems, the robot's design is currently in the development stage. The objective of the proposed system is to build a model with an intelligent agricultural monitoring technique linked to the main database, and the robot will have sufficient information to plant and cultivate crops without the need for human intervention [36].

A depth vision-based approach for detecting and placing truck containers is proposed for the joint harvesting system, along with three coordinate systems. This method included data preprocessing, point cloud poses transformation using the SVD (singular value decomposition) algorithm, upper edge segmentation and projection, RANSAC (Random Sample Consensus) algorithm edge line extraction and corner point positioning, and fusion and visualization of results on the depth image. Field trials show that the suggested approach is effective in identifying and positioning vehicles. However, the study is restricted due to its sensitivity to the appearance of truck containers and the presence of loud sites in the agricultural area. Autonomous driving and path planning in the forage harvester's unloading system is still challenging [37].

Intelligent robots have become extensively employed in various sectors as the intelligent computer industry with automation expands. Currently, manual labor is still used to harvest the majority of domestic crops. However, owing to constant worker pay hikes, the manual picking technique increases the fruit farmer's financial expenditures, and the appliances of robots in the farming business are challenging. As a result, the smart moveable robot picker has been introduced based on computer vision machinery by incorporating the robot arm, selector, flexible carrier, track procedure, and the intelligence unit, which accomplishes the robot picker's travel channel coding, auto-judging the ripe fruit, and in addition a vision-based binocular stereoscopic methodology employed for the functions of recognition and placement. To begin with, precise segmentation recognition and maturity evaluation of the target fruit is required for proper picking. Thus, the robot picker may potentially replace human labor in manual picking. The most important part of the recognition process is gathering fruit image samples, which is performed using a CCD camera that shoots following the preprocessed fruit features using image content. The color model is then built up, and it separates the fruit and surrounding surroundings using segmentation technology before recognizing the fruit. Additionally, it precisely traces 
and goes for the fruit location in relation to the three-dimensional coordinate information provided by the infrared source and the fruit contour and image differences taken by the two cameras simultaneously. To finish the picking operation, it must program the path recognition to avoid the obstacle [38]. The overall architecture of IoT-based fruit identification for harvesting is shown in Figure 4.

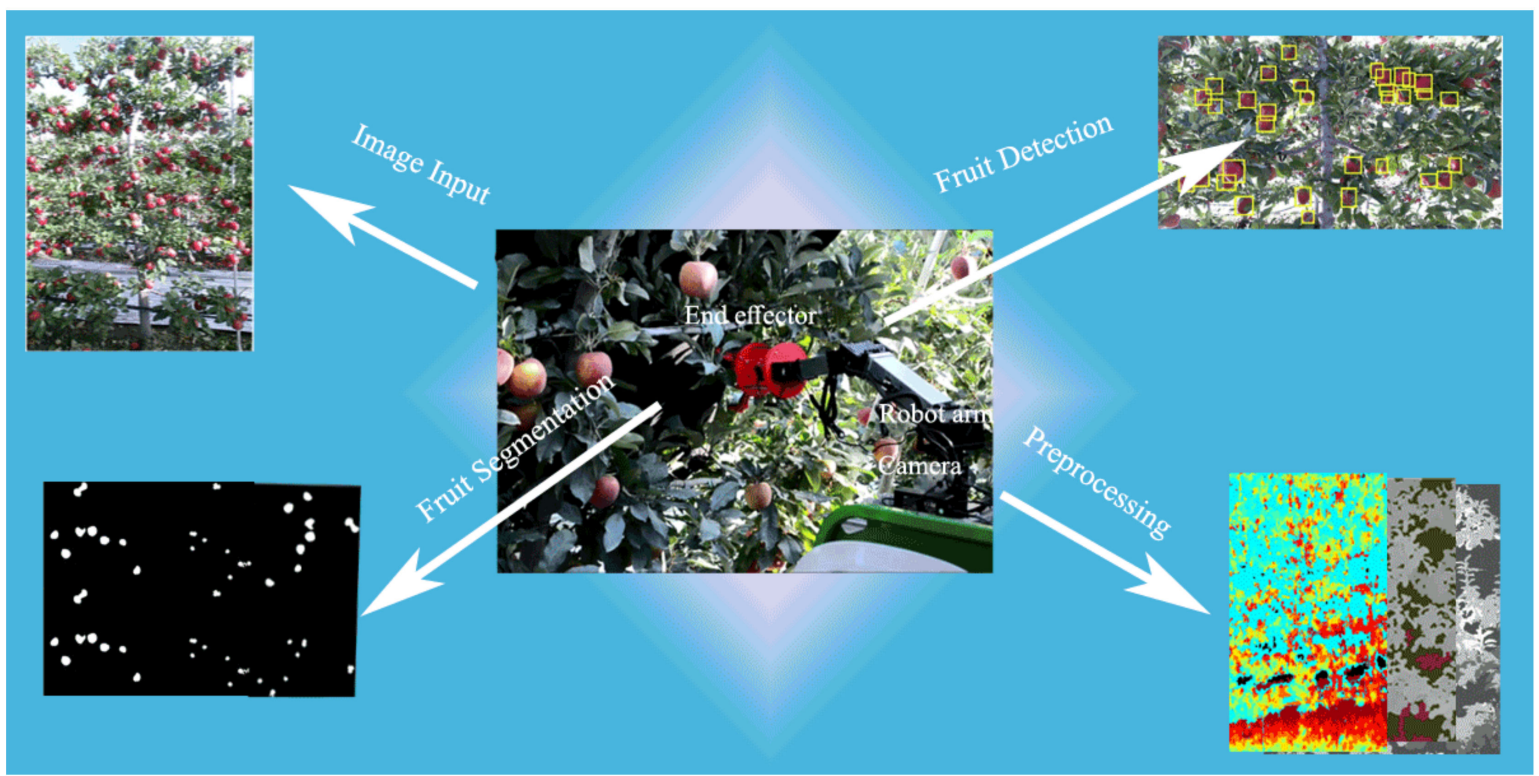

Figure 4. General architecture of IoT-based fruit detection for harvesting

\section{Open Issues and Key Challenges in Smart Agriculture}

The problems of deploying IoT-based agricultural systems are discussed in this section. The sensors' durability and cost are described. The IoT-based system requires a constant source of electricity. Depending on the size, a lot of electricity may be required. However, in rural and village communities, obtaining such electricity is challenging. To meet the energy requirement, alternative energy sources, such as solar and wind, must be employed. This will also raise the price significantly. It is necessary to have a dependable internet connection in rural and village regions. It is the most crucial aspect of establishing an IoT-based system. The connection must have a sufficient bandwidth to transport data in accordance with the application's requirements. Farmers need basic computer/tablet (HID device) training and an understanding of how the IoT system operates. It is also necessary to provide proper education on the unique IoT deployment in their farm [39].

There are six major obstacles to developing a green IoT-based agriculture system, involving infrastructure, mobility, maintenance, hardware, data privacy, data analytics, and data security. The selection of meters and sensors used for Internet of Things tools is one of the hardware issues. As a result, many different sensors may be utilized in Internet of Things applications, such as the water quality sensor, humidity sensor, chemical sensor, pressure sensor, temperature sensor, and more. The data analytics problem is machine learning, deep learning methods, and prediction algorithm applications in smart agriculture to produce a nutritional suspension using IoT records. Routine sensor inspections of all Internet of Things appliances are a maintenance issue while it may be certainly harmed in the farm area. The mobility problem is related to $4 \mathrm{G}, 5 \mathrm{G}, \mathrm{WiFi}, 6 \mathrm{LowPan}$, LoRa network connection, which link sensors spread across a broad region in the farm areas. Some infrastructural trials are developing and implementing Internet of Things-connected architectures that incorporate innovative technologies, such as cloud and fog computing and network virtualization. Finally, the primary issue in advancing smart agriculture based on IoT is not physical maintenance but rather ensuring security and privacy [8]. 
The UAVs that are linked wirelessly are subject to cyber-physical or harmful assaults to fool the control signals due to open communication lines. Such attempts represent a significant risk to the unmanned aerial vehicle system in terms of private information crash or theft, as well as mission failure. Moreover, the faking of control signals may harm the UAV mission and make it harder to restore it. As a result, improving UAV wireless communication's safety and confidentiality element, which necessitates in-depth research of security concerns covering the entire network protocol layers [40], is an important open subject.

Visual harvesting of robots' dynamic tracking of objects with great precision remains an unresolved challenge. Further study should also aim to enhance the precision placement and operation by merging smart behavior judgment, adequate fault tolerance, robot vision with artificial intelligence technology for accurate placement, and function enhancement. The recognition and location accuracy are impacted when the crop situation is varied due to the lighting and unconstrained circumstances of the field ecosystem. A robot vision approach would be efficient in harvesting crops correctly to increase the success rate of robotic harvesting in such settings. The researchers used geometric features, novel image algorithms, and intelligent decision theory to address the challenges. However, because massive datasets are necessary to train efficient deep learning algorithms, further study is needed [33]. Table 3 presents a comparison of the current state of the art on smart agriculture obstacles and benefits.

Table 3. Research studies organized by goal, methodologies, and technology employed, as well as obstacles and benefits.

\begin{tabular}{|c|c|c|c|c|}
\hline Authors & Research Purpose & $\begin{array}{c}\text { Technology } \\
\text { Used/Techniques }\end{array}$ & Findings and Challenges & Advantages \\
\hline [13] & Water management & $\begin{array}{l}\text { Bluetooth, Wi-Fi, RFID, } \\
\text { Zigbee, Raspberry pi }\end{array}$ & $\begin{array}{l}\text { Human interaction } \\
\text { Labor cost } \\
\text { Water consumption } \\
\text { Crop from irregular } \\
\text { irrigation. }\end{array}$ & $\begin{array}{l}\text { Can identify the moisture, } \\
\text { humidity, and temperature. } \\
\text { Consistent management of } \\
\text { all the regions containing } \\
\text { severe parts. }\end{array}$ \\
\hline [14] & Irrigation monitoring & $\begin{array}{c}\text { WSN, data } \\
\text { Analytics, node sensors } \\
\text { and web } \\
\text { Application }\end{array}$ & - & $\begin{array}{l}\text { Optimal irrigation of the } \\
\text { water for } \\
\text { farming crops. }\end{array}$ \\
\hline [20] & $\begin{array}{l}\text { Crop management } \\
\text { Irrigation } \\
\text { management }\end{array}$ & $\begin{array}{c}\text { Mobile technology, } \\
\text { GPRS, Wi-Fi, Raspberry } \\
\text { pi, Zig Bee }\end{array}$ & $\begin{array}{c}\text { Unstable weather } \\
\text { water shortage, irregular } \\
\text { water usage }\end{array}$ & Improve the yield, low cost \\
\hline [38] & Harvesting nodes & $\begin{array}{l}\text { WSN, Solar } \\
\text { energy system. Image } \\
\text { processing technique. }\end{array}$ & - & $\begin{array}{l}\text { Prevents data loss and } \\
\text { collusion, } \\
\text { increases the lifetime of } \\
\text { WSN. }\end{array}$ \\
\hline [41] & Crop growth & $\begin{array}{c}\text { green-crop gCrop } \\
\text { based on ML model, } \\
\text { Wireless Sensor } \\
\text { Network and Internet } \\
\text { of Things }\end{array}$ & $\begin{array}{l}\text { Obtained accuracy was } \\
98 \% \text { using polynomial of } \\
\text { third-degree of Regression } \\
\text { model while the } \\
\text { computation time is very } \\
\text { high. }\end{array}$ & - \\
\hline [42] & $\begin{array}{c}\text { Nutrient } \\
\text { Management }\end{array}$ & $\begin{array}{c}\text { Raspberry pi } \\
\text { Mobile technology } \\
\text { Wi-Fi }\end{array}$ & $\begin{array}{l}\text { Low or high watering. } \\
\text { Lack of nutrition } \\
\text { management. }\end{array}$ & $\begin{array}{l}\text { Can monitor weather } \\
\text { conditions. } \\
\text { Cost-effective } \\
\text { Automatically monitored } \\
\text { disease associated with rice } \\
\text { species. }\end{array}$ \\
\hline
\end{tabular}


Table 3. Cont.

\begin{tabular}{|c|c|c|c|c|}
\hline Authors & Research Purpose & $\begin{array}{c}\text { Technology } \\
\text { Used/Techniques }\end{array}$ & Findings and Challenges & Advantages \\
\hline$[43]$ & Crop Productivity & $\begin{array}{c}\text { Big data } \\
\text { storage and analytics, } \\
\text { IoT, Data } \\
\text { Mining, Cloud } \\
\text { computing, Data } \\
\text { Analytics. }\end{array}$ & - & $\begin{array}{c}\text { Network architecture, } \\
\text { platform } \\
\text { and design helps access to } \\
\text { IoT, } \\
\text { improves crop productivity, } \\
\text { Provides an overview of } \\
\text { IoT } \\
\text { applications, sensors, } \\
\text { protocols } \\
\text { And data-enabled } \\
\text { technologies. }\end{array}$ \\
\hline
\end{tabular}

One of the most challenging aspects of robotic grasping is estimation. Traditional techniques have limitations since noise or partial loss of the point cloud might impact the estimation's accuracy and resilience. Estimation is more difficult in orchard situations than it was in interior environments.

\section{Data Handling and Processing}

Traditional vision algorithms' performance is constantly restricted in complicated and volatile settings [34]. World food consumption is predicted to treble by 2050 due to population expansion and societal progress, yet increasing food production is now difficult due to declining water, climate alterations, less proper soil, and insects and illnesses. Pests and diseases have always been significant stumbling blocks to increased grain output. Satellite technology is climate sensitive and has a limited illumination variation, making it challenging to satisfy the requirement for insects and infection management in farming areas. Currently, low-altitude autonomous drones (offering excellent flexibility and image resolution) can satisfy the needs of agricultural insect and infection management. In some circumstances, such as when there is a high wind, drone stability might be difficult. As a result, the drone's flight route must be designed in conjunction with the actual conditions. Long flights are necessary for field pest and disease data collection; thus, choosing a sunny day with a moderate breeze might be a viable alternative [32]. Identifying malicious and compromised nodes among soil sensors interacting with the base station is a significant problem in the base station to cloud communications. The trust management method is presented as one of the options for identifying these nodes in a lightweight manner.

Finally, the study highlighted the existing problems and possibilities and future research in vegetable and fruit identification and placement. The majority of previous research showed that illumination variations, grouping, and unconstrained situations have been the main obstacles to effective recognition and localization of vegetables and fruits in the field. Further research will be required to overcome the existing state-of-the-art challenges and enhance the performance, accuracy, efficiency, effectiveness, recognition, and success rate of controlling and image processing techniques. However, fruit recognition, detection, positioning, harvesting robots, and application robustness enhancement need to minimize the inclusive computational cost and time. Future research might include algorithms and camera operation advancements, sensor platforms that can enhance illumination consistently, horticultural changes, and human-machine collaboration [29]. Furthermore, sophisticated methodologies, algorithms, and computational approaches are necessary to address the lack of precision in harvesting operations.

\section{Discussion and Analysis}

It is estimated that plant diseases are a significant contributor to global financial deficits. Numerous abiotic and biotic stresses and continual tension monitoring concerns the impacts of the loss of fruit-producing plants. Consequently, the $\$ 15$ billion U.S. apple 
industry loses millions of dollars every year. Fruits are one of the most significant sources of nutrients in plants; yet, illnesses, pests, fungous, infectious, and microbial diseases all affect the quality and quantity of fruits. Using computer vision-based methods, the issue may now be alleviated. Diseases/infections may be detected early and effectively using these methods.

The sickness classification of various fruit leaves was achieved using a deep convolutional neural network DCNN approach. The deep features are retrieved by first utilizing deep learning networks, such as AlexNet and VGG-s, and then tweaked using a transfer learning approach. Before the selection step, a multi-level fusion strategy is offered, and the chosen features analyzed to produce the entropy basis features. To categorize the obtained feature map, we employed a multi-SVM classifier. The diseases investigated in the experiments include apple rust, scab, black rot, peach bacterial spots, and cherry powdery mildew, and they were all gathered from a plant village dataset. The recommended method's better performance in terms of a 97.8\% accuracy, $97.6 \%$ sensitivity, $97.6 \%$ precision, and G-measure was observed in the classification results (97.6\%) [44]. Some research has investigated whether computer vision approaches may be employed for scalable and early plant sickness detection. There is still a critical lack of non-lab data sets that can be utilized to allow vision-based plant disease detection. For visual plant disease identification, the PlantDoc dataset was supplied. The collection has 2598 data points in total, encompassing 13 plant species and up to 17 disease categories, and was developed by annotating internetscraped photos for 300 human hours. Three models for plant disease classification were trained to illustrate the dataset's effectiveness. The findings demonstrate that employing our dataset models may enhance the recognition rate by up to $31 \%$. The recommended dataset, we feel, will contribute to decreasing the entry barrier for computer vision algorithms in plant disease detection. For photos featuring leaves from various classes in a dataset with contextual noise, and low-resolution leaf images, the model fails to give proper conclusions. Using image segmentation methods to extract leaves from the photos can boost the dataset's utility. Although the dataset has been rigorously verified, particular photographs in the collection may be wrongly labeled owing to a lack of sufficient topic knowledge [45].

It is necessary to construct an improved VGG16-based DCNN model to detect apple leaf diseases (scab, frogeye spots, and cedar rust). The global average pooling layer replaces the fully connected layer to lessen restrictions and a batch normalization layer is attached to boost the model's computational performance. Furthermore, to avoid a long training time, a transfer learning approach is applied. To detect apple leaf diseases, the suggested model makes use of 2446 apple leaves, 2141 photos in the training phase and 305 images in the testing phase. The experimental data reveal that utilizing the recommended approach, the total accuracy of apple leaf classification may reach $99.01 \%$. Furthermore, the findings demonstrate that cedar rust is accurately diagnosed, but one healthy person is misclassified as scab and the other as frogeye spots.

Furthermore, the model parameters are cut by $89 \%$ compared to the standard VGG16. As a result, the classification performance is raised by $6.3 \%$, and the computational complexity is cut to $0.56 \%$ of the innovative model. Consequently, the DCNN model developed in this study provides a more accurate and speedier way for recognizing apple leaf infections [46]. Table 4 compares the efficiency of several smart agricultural techniques. 
Table 4. Comparative analysis of different methods based on smart agriculture.

\begin{tabular}{|c|c|c|c|c|c|c|c|c|c|}
\hline Ref. & Technique & Dataset & Disease Classes & Accuracy & Sensitivity & Precision & Recall & $\begin{array}{l}\text { F1 Mea- } \\
\text { sure }\end{array}$ & $\begin{array}{l}\text { G Mea- } \\
\text { sure }\end{array}$ \\
\hline$[44]$ & $\begin{array}{l}\text { DCNN } \\
{[\mathrm{VGG}+} \\
\text { AlexNet] }\end{array}$ & $\begin{array}{c}\text { plant } \\
\text { village } \\
\text { dataset }\end{array}$ & $\begin{array}{c}5 \text { (apple rust, scab } \\
\text { black rot, cherry } \\
\text { powdery mildew, and } \\
\text { peach bacterial spots) }\end{array}$ & $97.8 \%$ & $97.6 \%$ & $97.6 \%$ & - & - & $97.6 \%$ \\
\hline$[46]$ & $\begin{array}{l}\text { DCNN } \\
\text { [en- } \\
\text { hanced } \\
\text { VGG16] }\end{array}$ & $\begin{array}{l}2446 \\
\text { apple } \\
\text { leaves }\end{array}$ & $\begin{array}{l}4 \text { (apple leaf diseases } \\
\text { (Scab, frogeye spots, } \\
\text { cedar rust and healthy) }\end{array}$ & $99.01 \%$ & - & $99.02 \%$ & $99.02 \%$ & $99.02 \%$ & - \\
\hline$[47]$ & $\begin{array}{l}\text { enhanced } \\
\text { CNN } \\
\text { [AlexNet] }\end{array}$ & $\begin{array}{l}\text { Enhanced } \\
\text { Plant } \\
\text { Village }\end{array}$ & 52 & $99.11 \%$ & - & $99.49 \%$ & $99.11 \%$ & $99.29 \%$ & - \\
\hline$[48]$ & $\begin{array}{c}\text { IoT } \\
\text { [WSNs } \\
+\mathrm{ML} \\
\text { algo- } \\
\text { rithms] }\end{array}$ & $\begin{array}{l}\text { Different } \\
\text { data }\end{array}$ & - & $81.6 \%$ & - & - & - & - & - \\
\hline [49] & $\begin{array}{l}\text { AlexNet } \\
\text { deep } \\
\text { learning } \\
\text { algo- } \\
\text { rithm }\end{array}$ & $\begin{array}{l}54,306 \\
\text { images }\end{array}$ & $\begin{array}{c}14 \text { crop species and } 26 \\
\text { diseases }\end{array}$ & $97.38 \%$ & - & $97.42 \%$ & $97.37 \%$ & $97.36 \%$ & \\
\hline$[50]$ & $\begin{array}{l}\text { LeNet } \\
\text { DL tech- } \\
\text { nique } \\
\text { (X- } \\
\text { Fideo) }\end{array}$ & PlantVillage & 3 & $98.60 \%$ & - & $98.82 \%$ & $97.18 \%$ & $96.89 \%$ & - \\
\hline
\end{tabular}

For the recognition and detection of olive diseases, such as peacock spot, anthracnose, and canker, an improved convolutional neural network (CNN) dubbed AlexNet was suggested. Several innovations separate the proposed model from others. It uses effective intelligent data preprocessing with a stable image in each class, a transfer learning approach, and an extended and upgraded PlantVillage dataset to work in more complicated situations. The total accuracy of the suggested technique is $99.11 \%$, which is the best possible score. Furthermore, it possesses precision, recall, and F1 measures of $99.49 \%, 99.11 \%$, and $99.29 \%$, respectively. Despite the fact that model training takes a long time, classification during testing takes only a few seconds on a CPU [47]. Citrus fruits, leaves, and stems are included in the image dataset. The collection contains images of normal and diseased citrus leaves and fruits, including greening, scab, blackspot, canker, and melanosis. There are 759 images of normal and abnormal citrus leaves and fruits in the data collection. The images had a resolution of $5202 \times 3465$ (Mpix), and when scaled at $72 \mathrm{dpi}$, the width and height were $256 \times 256$ pixels, correspondingly. The contaminated images were divided into four various citrus illnesses and left on their own. The entire process consists of four major steps: (a) enhancing the dataset using Top-hat and then Gaussian functions; (b) weighted segmentation and segmentation of lesion through a saliency map, which highlights the infested area; (c) color, texture, and geometric feature extraction from the diseased area; and (d) PCA, skewness, and entropy-based feature selection and implementation.

Agriculture management, water contamination, and air quality analysis monitoring systems were all investigated as part of the smart environment monitoring (SEM) system. Figure 5 demonstrates that substantial investigation of smart environment monitoring has increased over the period in both cases, specifically research involving the wireless sensor network and Internet of Things along with research involving machine learning and Internet of Things [41,51]. 


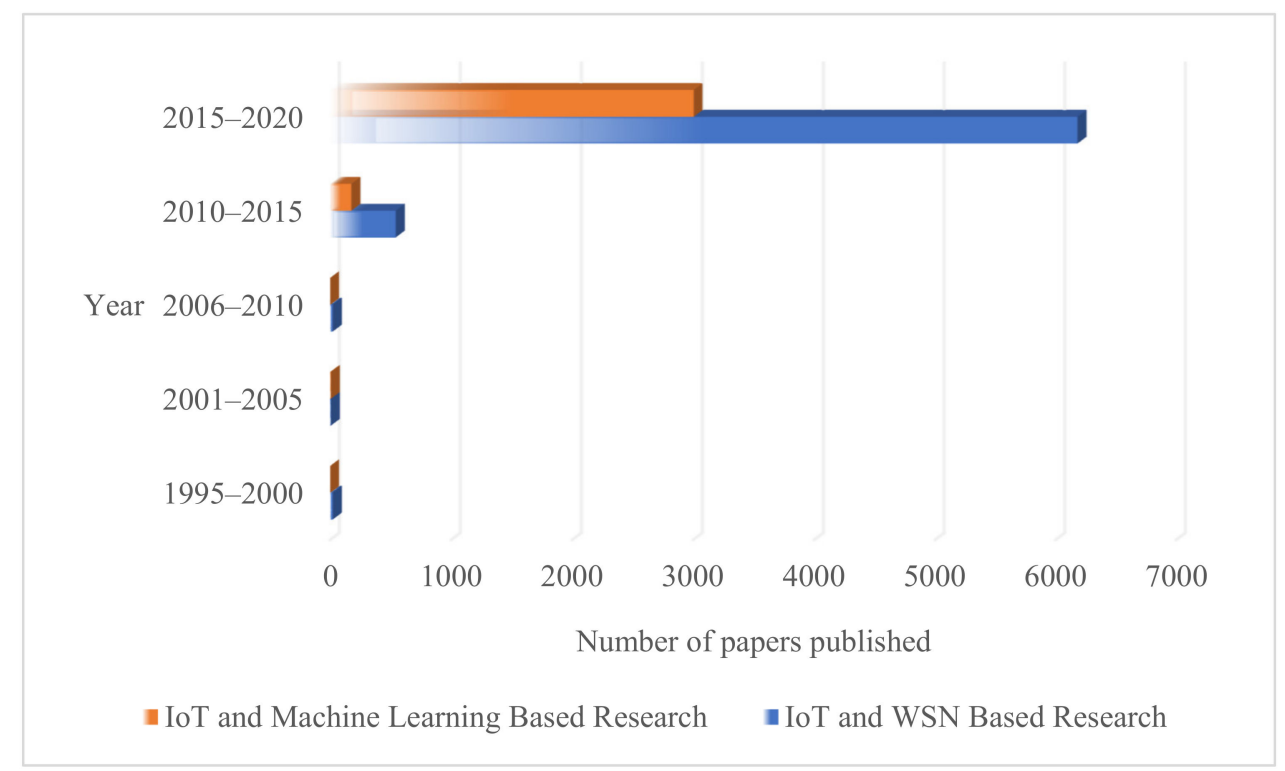

Figure 5. Research contribution using IoT, WSN, and machine learning.

Imperfect network access, lack of a (or no) power supply, and high framework costs compared to an ordinary farmer's income were presented in a low-cost, energy-proficient, protected, dependable, and heterogeneous three-layer approach for Internet of Thingsbased smart agriculture. IoT devices make up the first layer, including IoT-based smart agriculture monitoring like insect detection, theft detection, crop monitoring, smart irrigation, smart poultry, food supply chain, and food preservation monitoring systems. The low-power LoRaWAN network connects the IoT devices to the gateways. The next layer is made up of local processing servers and gateways that are connected with the gateways. The cloud layer, which uses the publicly available FIWARE framework to offer a set of open-source API standards, is the third layer. This study aimed to create diagnostic techniques for packet combination procedures at the fog node before they were sent over the network facility to cloud servers. This aims to decrease short IoT packet processing overheads and optimize energy usage at the backbone, as billions of IoT devices linked to fog nodes are projected to generate massive volumes of short IoT packets [52].

A Cuckoo Search Algorithm has been created, allowing water allocated for farming under all situations. Temperature, turbidity, $\mathrm{pH}$, and moisture were collected utilizing the Internet of Things (IoT) infrastructure outfitted with wireless communication devices and sensors. ThingSpeak presented the sensor data in the cloud system in this IoT platform. The ThingSpeak data was utilized in the suggested Cuckoo Search Algorithm, which identified suitable yields for a given soil [53]. Incorrect or late identification can result in overuse or underuse of chemicals, resulting in higher production costs and environmental and health consequences. With varied lighting, angles, surfaces, noise, and high resolutions, 3651 real-time indication images of various apple infections were manually collected. A subset of this dataset was labeled by experts, such as cedar apple rust, scab, and normal leaves, and open-sourced for the Plant Pathology Challenge to Kaggle community. We also used this data to train a standard CNN (convolutional neural network), which obtained $97 \%$ recognition on a held-out test set and a maximum AUC value of 0.986 . The project's goal was to keep adding additional images to the pilot dataset from various perspectives, lighting, and distances to create a bigger more complete labeled database by experts. The dataset will contain pests and diseases, such as apple mites and aphids and apple leaves comprising apple marssonina and alternaria leaf blotch, leaf spot, frogeye, rot, cedar, and powdery mildew, fire blight, and scab-labeled images.

Additionally, it will be photographed and remarked on fruit infected with apple brown rot, bitter rot, or scab [54]. An Internet of Things-based cost-effective monitoring system was developed to address particular crop irrigation, soil erosion, and irregular irrigation. 
The suggested method entails building a distributed WSN (wireless sensor network), with multiple sensor modules covering each part of the farm and transferring data to a central server. ML techniques will aid irrigation pattern forecasts based on yields and climate environments. According to a comparison of several algorithms, random forest regression has a decent accuracy of $81.6 \%$. However, due to harsh weather conditions, the system is constrained in many ways: the forecast accuracy is dependent on the setup's correct installation, and the threat of wild animals can harm the hardware setup [48]. Because human abilities and agricultural gear are severely restricted compared to robot knowledge, robotic systems in agriculture can be highly beneficial in achieving both high quality and quantity goods. To integrate IoT systems with agricultural machinery, a new way of managing control signals from the control system to the actuators is required. These methods should increase economic viability while also lowering environmental impact and enhancing food sustainability. It handles various agricultural tasks, including moisture sensing, irrigation, crop monitoring, and insect and animal defense [55]. Accordingly, a state-of-the-art technologies-based accuracy comparison is presented in Figure 6.

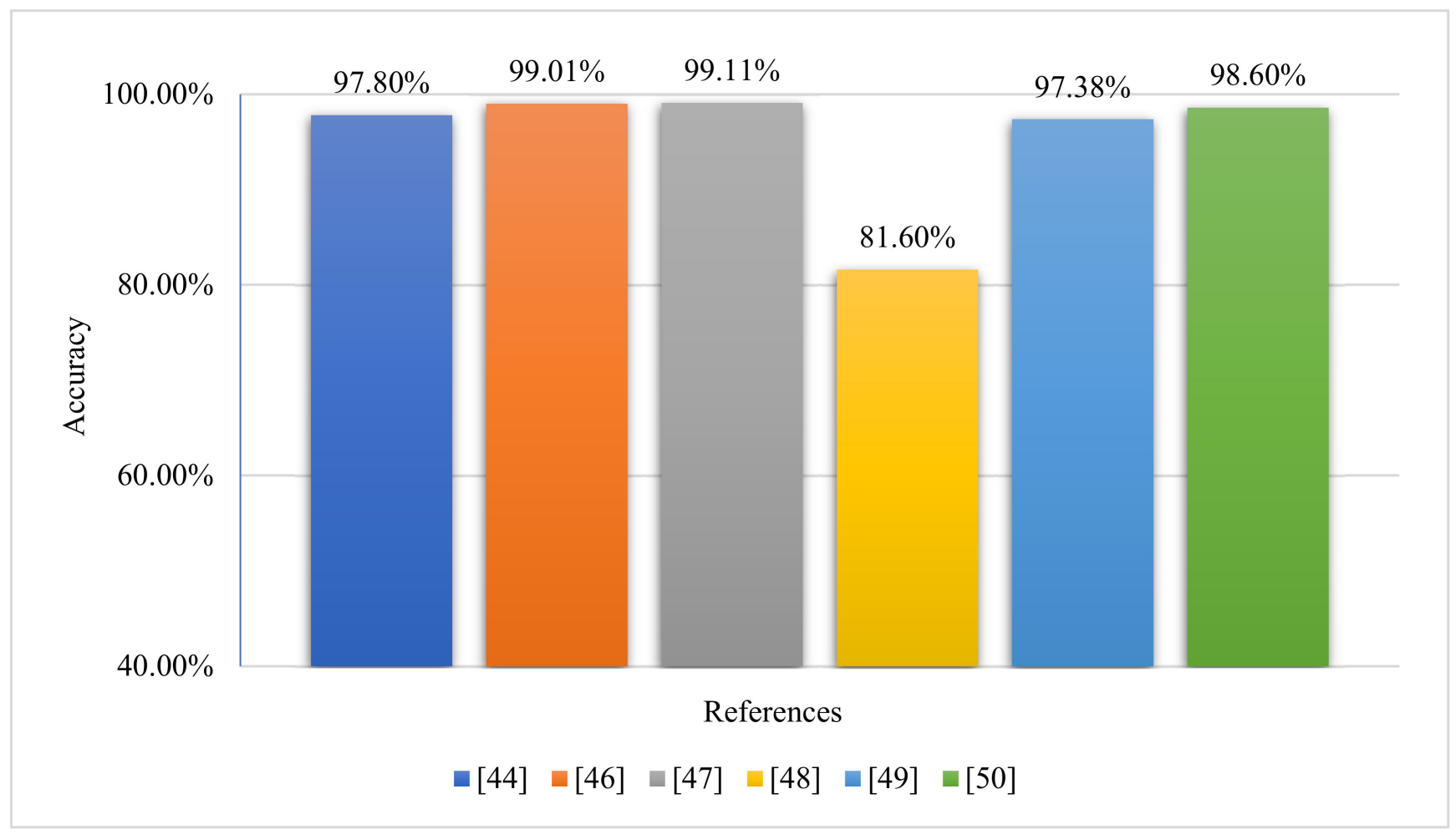

Figure 6. Accuracy-based analysis of the different state of the art techniques.

Water monitoring is the most highly measured IoT sub-vertical, followed by crop, smart agriculture, animal, and irrigation monitoring. All of these have the same proportion of peer-reviewed articles exploring the possible uses of the Internet of Things. According to the findings, the most important sensor data for measurement is $15.73 \%$ soil moisture, $19.79 \%$ humidity, and $24.87 \%$ ambient temperature. However, further sensor information, such as soil $\mathrm{pH}$ and moisture, are also collected for IoT applications. Wi-Fi has the highest claimed use in farming and agriculture, with $30.27 \%$ and $21.10 \%$ use of mobile tools, as shown in Figure 7. Other technologies like Bluetooth, WSN, RFID, Raspberry Pi, ZigBee, LoRa, and GPRS are less popular in the agriculture and farming industries. In the agricultural and farming business comparison, the farming sector uses IoT for automation slower [42]. The Plant Server and User View were created with phpMyAdmin to manage MySQL server management. The F-RCNN-qualified model for anomaly detection had $80 \%$ confidence, while the technique for the transfer of learning illness had $95.75 \%$ accu- 
racy. In reality, automatic image capturing software was deployed, and the RCNN model successfully recognized $91.67 \%$ of tomato plant illnesses [56].

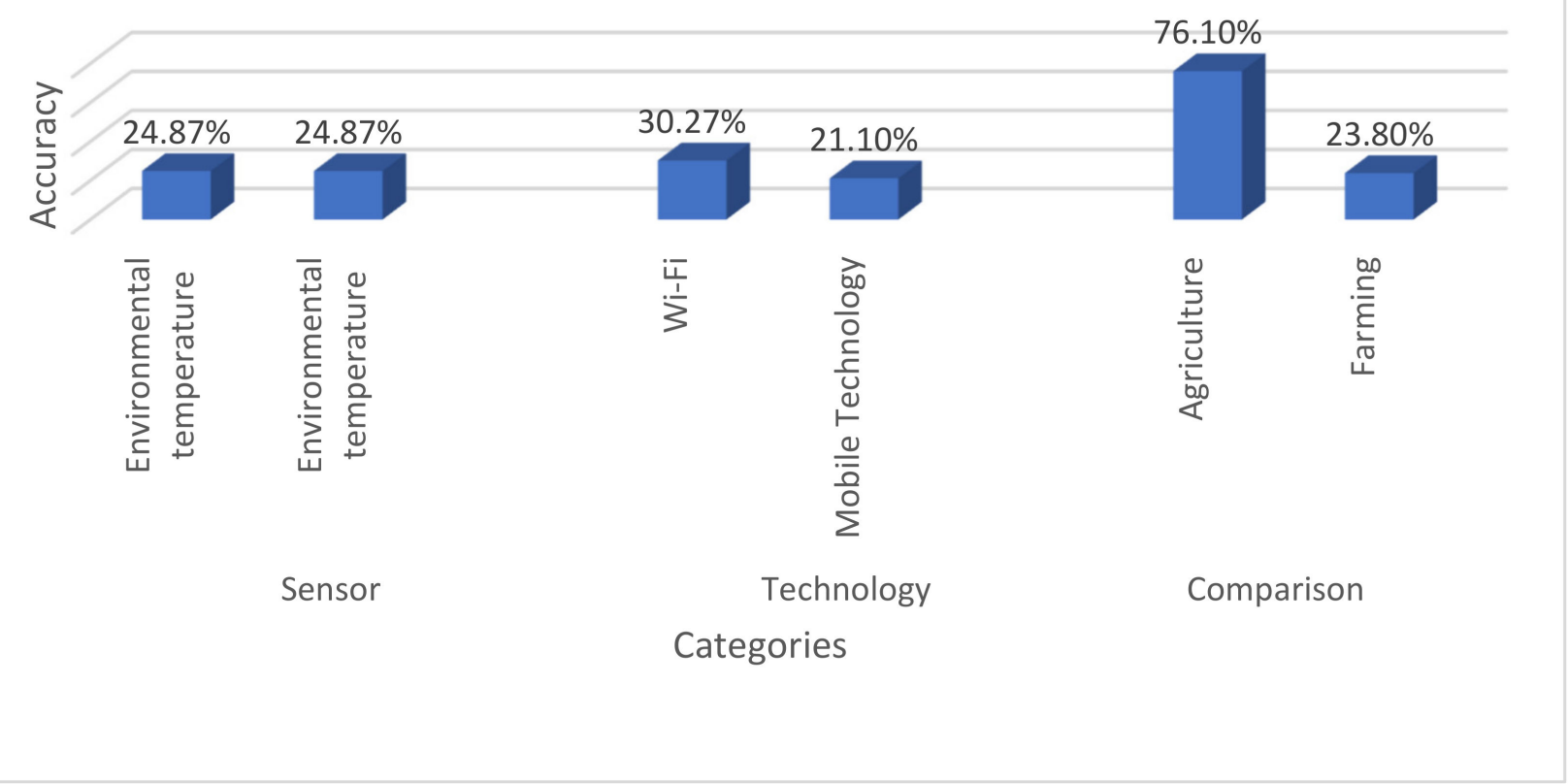

Figure 7. An overview of 60 published articles on sensor and technology-based data collection, as well as a comparison of agriculture and farming utilizing IoT.

\section{Conclusions and Future Directions}

The implementation of sustainable communication technologies and sensors based on IoT is necessary to increase agricultural productivity. Wireless sensors, unmanned aerial vehicles, and cloud computing have been shown to be practical tools for guaranteeing long-term agricultural productivity. Many processes throughout the production cycle, including irrigation, soil sample and mapping, fertilizer or pest control, yield monitoring, forecasting, and harvesting, may be automated using smart devices, allowing for improved crop quality and growth capacity. The key effective features, important applications, IoTbased smart agriculture technology and equipment, and open barriers and possibilities were all examined in this study. This research will be expanded in the future to include security and privacy issues in smart agriculture using IoT methods.

Author Contributions: All authors contributed equally and scientifically. All authors have read and agreed to the published version of the manuscript.

Funding: No specific funding received for this research.

Acknowledgments: This research is supported by Artificial Intelligence \& Data Analytics Lab (AIDA) CCIS Prince Sultan University, Riyadh, Saudi Arabia. The authors also would like to acknowledge the support of Prince Sultan University for paying the Article Processing Charges (APC) of this publication.

Conflicts of Interest: There is no conflict of interest to declare. 


\section{References}

1. Mukhtar, H.; Khan, M.Z.; Khan, M.U.G.; Saba, T.; Latif, R. Wheat Plant Counting Using UAV Images Based on Semi-supervised Semantic Segmentation. In Proceedings of the 2021 1st International Conference on Artificial Intelligence and Data Analytics (CAIDA), Riyadh, Saudi Arabia, 6-7 April 2021; pp. 257-261.

2. Khan, M.A.; Akram, T.; Sharif, M.; Alhaisoni, M.; Saba, T.; Nawaz, N. A probabilistic segmentation and entropy-rank correlationbased feature selection approach for the recognition of fruit diseases. EURASIP J. Image Video Process. 2021, 2021, 14. [CrossRef]

3. Khan, M.A.; Akram, T.; Sharif, M.; Awais, M.; Javed, K.; Ali, H.; Saba, T. CCDF: Automatic system for segmentation and recognition of fruit crops diseases based on correlation coefficient and deep CNN features. Comput. Electron. Agric. 2018, 155, 220-236. [CrossRef]

4. Safdar, A.; Khan, M.A.; Shah, J.H.; Sharif, M.; Saba, T.; Rehman, A.; Javed, K.; Khan, J.A. Intelligent microscopic approach for identification and recognition of citrus deformities. Microsc. Res. Tech. 2019, 82, 1542-1556. [CrossRef] [PubMed]

5. Sinha, B.B.; Dhanalakshmi, R. Recent advancements and challenges of Internet of Things in smart agriculture: A survey. Futur. Gener. Comput. Syst. 2022, 126, 169-184. [CrossRef]

6. Kolivand, H.; Fern, B.M.; Saba, T.; Rahim, M.S.M.; Rehman, A. A New Leaf Venation Detection Technique for Plant Species Classification. Arab. J. Sci. Eng. 2019, 44, 3315-3327. [CrossRef]

7. Friha, O.; Ferrag, M.A.; Shu, L.; Maglaras, L.; Wang, X. Internet of Things for the Future of Smart Agriculture: A Comprehensive Survey of Emerging Technologies. IEEE/CAA J. Autom. Sin. 2021, 8, 718-752. [CrossRef]

8. Kianat, J.; Khan, M.A.; Sharif, M.; Akram, T.; Rehman, A.; Saba, T. A joint framework of feature reduction and robust feature selection for cucumber leaf diseases recognition. Optik 2021, 240, 166566. [CrossRef]

9. Saba, T.; Rehman, A.; AlGhamdi, J.S. Weather forecasting based on hybrid neural model. Appl. Water Sci. 2017, 7, 3869-3874. [CrossRef]

10. Sharma, Y.; Tyagi, V.; Datta, P. IoT based smart agriculture monitoring system. Int. J. Innov. Technol. Explor. Eng. 2020, 9, 325-328.

11. Fern, B.M.; Rahim, M.S.M.; Saba, T.; Almazyad, A.S.; Rehman, A. Stratified classification of plant species based on venation state. Biomed. Res. 2017, 28, 5660-5663.

12. Sudarshan, K.; Hegde, R.R.; Sudarshan, K.; Patil, S. Smart agriculture monitoring and protection system using IoT. Perspect. Commun. Embed. Syst. Signal Process. PiCES 2019, 2, 308-310.

13. Rajaram, K.; Sundareswaran, R. IoT Based Crop-Field Monitoring and Precise Irrigation System Using Crop Water Requirement. In International Conference on Computational Intelligence in Data Science; Springer: Cham, Switzerland, 2020; pp. 291-304.

14. Abba, S.; Wadumi Namkusong, J.; Lee, J.A.; Liz Crespo, M. Design and Performance Evaluation of a Low-Cost Autonomous Sensor Interface for a Smart IoT-Based Irrigation Monitoring and Control System. Sensors 2019, 19, 3643. [CrossRef]

15. Kamaruddin, F.; Abd Malik, N.N.N.; Murad, N.A.; Latiff, N.M.A.A.; Yusof, S.K.S.; Hamzah, S.A. IoT-based intelligent irrigation management and monitoring system using Arduino. Telkomnika 2019, 17, 2378-2388. [CrossRef]

16. Akshaya, M.; Kavipriya, P.R.; Yogapriya, M.; Karthikamani, R. IoT based fertilizer injector for agricultural plants. Int. Res. J. Eng. Technol. 2020, 7, 2950-2954.

17. Reddy, H.S.; Hedge, G.; Chinnayan, D.R. IOT based leaf disease detection and fertilizer recommendation. Int. J. Innov. Technol. Explor. Eng. 2019, 9, 132-136.

18. Chavan, R.; Deoghare, A.; Dugar, R.; Karad, P. IoT Based Solution for Grape Disease Prediction Using Convolutional Neural Network and Farm Monitoring. Int. J. Sci. Res. Eng. Dev. 2019, 2, 494-500.

19. Bhoi, S.K.; Jena, K.K.; Panda, S.K.; Long, H.V.; Kumar, R.; Subbulakshmi, P.; Bin Jebreen, H. An Internet of Things assisted Unmanned Aerial Vehicle based artificial intelligence model for rice pest detection. Microprocess. Microsyst. 2021, 80, 103607. [CrossRef]

20. Ganesh, P.; Tamilselvi, K.; Karthi, P. Crop prediction by monitoring temperature and rainfall using decision tree with IoT and cloud-based system. Proceedings of the International Conference on Computational Intelligence and Data Science, Gurugram, India, 7-8 April 2018, 1-9.

21. Tolentino, L.K. Yield evaluation of Brassica rapa, Lactuca sativa, and Brassica integrifolia using image processing in an IoT-based aquaponics with temperature-controlled greenhouse. AGRIVITA J. Agric. Sci. 2020, 42, 393-410. [CrossRef]

22. Visconti, P.; Giannoccaro, N.I.; de Fazio, R.; Strazzella, S.; Cafagna, D. IoT-oriented software platform applied to sensors-based farming facility with smartphone farmer app. Bull. Electr. Eng. Inform. 2020, 9, 1095-1105. [CrossRef]

23. Kodali, R.K.; Rajanarayanan, S.C.; Boppana, L. IoT based Weather Monitoring and Notification System for Greenhouses In Proceedings of the 2019 11th International Conference on Advanced Computing (ICoAC), Chennai, India, 18-20 December 2019; pp. 342-345.

24. Ariffin, M.A.M.; Ramli, M.I.; Amin, M.N.M.; Ismail, M.; Zainol, Z.; Ahmad, N.D.; Jamil, N. Automatic Climate Control for Mushroom Cultivation Using IoT Approach. In Proceedings of the 2020 IEEE 10th International Conference on System Engineering and Technology (ICSET), Shah Alam, Malaysia, 9 November 2020; pp. 123-128.

25. Nagamani, P.; Sundari Jahnavi, M.; Govind Raju, N.N.; Bhanu Shankar, A.; Govind Reddy, K.S. Smart Hydroponics Water Monitoring Using IoT. J. Emerg. Technol. Innov. Res. 2019, 6, 114-120.

26. Jayasuriya, Y.P.; Elvitigala, C.S.; Wamakulasooriya, K.; Sudantha, B. Low Cost and IoT Based Greenhouse with Climate Monitoring and Controlling System for Tropical Countries. In Proceedings of the 2018 International Conference on System Science and Engineering (ICSSE), New Taipei, Taiwan, 28-30 June 2018; pp. 1-6. 
27. Boursianis, A.D.; Papadopoulou, M.S.; Diamantoulakis, P.; Liopa-Tsakalidi, A.; Barouchas, P.; Salahas, G.; Karagiannidis, G.; Wan, S.; Goudos, S.K. Internet of Things (IoT) and Agricultural Unmanned Aerial Vehicles (UAVs) in smart farming: A comprehensive review. Internet Things 2020, 100187. [CrossRef]

28. Odesola, D.F.; Olivarez, R.; Ramos, A.; Malolos, D.; Patrick, V.; Balba, N.P. Internet of things (IoT) based home automated weather monitoring system. LPU-Laguna J. Eng. Comput. Stud. 2019, 4, 1-10.

29. Fu, L.; Gao, F.; Wu, J.; Li, R.; Karkee, M.; Zhang, Q. Application of consumer RGB-D cameras for fruit detection and localization in field: A critical review. Comput. Electron. Agric. 2020, 177, 105687. [CrossRef]

30. Dutta, J.; Dutta, J.; Gogoi, S. Smart farming: An opportunity for efficient monitoring and detection of pests and diseases. J. Entomol. Zool. Stud. 2020, 8, 2352-2359.

31. Maslekar, N.V.; Kulkarni, K.P.; Chakravarthy, A.K. Application of Unmanned Aerial Vehicles (UAVs) for Pest Surveillance, Monitoring and Management. In Innovative Pest Management Approaches for the 21st Century; Springer: Berlin, Germany, 2020; pp. $27-45$.

32. Gao, D.; Sun, Q.; Hu, B.; Zhang, S. A Framework for Agricultural Pest and Disease Monitoring Based on Internet-of-Things and Unmanned Aerial Vehicles. Sensors 2020, 20, 1487. [CrossRef]

33. Tang, Y.; Chen, M.; Wang, C.; Luo, L.; Li, J.; Lian, G.; Zou, X. Recognition and Localization Methods for Vision-Based Fruit Picking Robots: A Review. Front. Plant Sci. 2020, 11, 510. [CrossRef] [PubMed]

34. Kang, H.; Zhou, H.; Wang, X.; Chen, C. Real-Time Fruit Recognition and Grasping Estimation for Robotic Apple Harvesting. Sensors 2020, 20, 5670. [CrossRef]

35. Ogorodnikova, O.M.; Ali, W. Method of ripe tomato detecting for a harvesting robot. In AIP Conference Proceedings; AIP Publishing LLC: Melville, NY, USA, 2019.

36. Yeshmukhametov, A.; Al Khaleel, L.; Koganezawa, K.; Yamamoto, Y.; Amirgaliyev, Y.; Buribayev, Z. Designing of CNC Based Agricultural Robot with a Novel Tomato Harvesting Continuum Manipulator Tool. Int. J. Mech. Eng. Robot. Res. 2020, 9, 876-881. [CrossRef]

37. Zhang, W.; Gong, L.; Chen, S.; Wang, W.; Miao, Z.; Liu, C. Autonomous Identification and Positioning of Trucks during Collaborative Forage Harvesting. Sensors 2021, 21, 1166. [CrossRef]

38. Li, B.; Zhou, A.; Yang, C.; Zheng, S. The Design and Realization of fruit Harvesting Robot Based on IOT. In Proceedings of the 2016 International Conference on Computer Engineering, Information Science E Application Technology (ICCIA 2016); Atlantis Press: Amstelkade, AV, USA, 2016.

39. Rahaman, S.H.; Biswas, S. Advantages of Internet of Things (IoT) and It's Applications in Smart Agriculture System. Int. Res. J. Adv. Sci. Hub 2020, 2, 4-10. [CrossRef]

40. Mishra, D.; Natalizio, E. A survey on cellular-connected UAVs: Design challenges, enabling 5G/B5G innovations, and experimental advancements. Comput. Netw. 2020, 182, 107451. [CrossRef]

41. Ullo, S.L.; Sinha, G.R. Advances in Smart Environment Monitoring Systems Using IoT and Sensors. Sensors 2020, $20,3113$. [CrossRef]

42. Madushanki, R.; Wirasagoda, H.; Halgamuge, M. Adoption of the Internet of Things (IoT) in agriculture and smart farming towards urban greening: A review. Int. J. Adv. Comput. Sci. Appl. (IJACSA) 2019, 1. [CrossRef]

43. Vikranth, K. An Implementation of IoT and Data Analytics in Smart Agricultural System-A Systematic Literature Review. Int. J. Manag. Technol. Soc. Sci. 2021, 6, 41-70. [CrossRef]

44. Khan, M.A.; Akram, T.; Sharif, M.; Saba, T. Fruits diseases classification: Exploiting a hierarchical framework for deep features fusion and selection. Multimed. Tools Appl. 2020, 79, 25763-25783. [CrossRef]

45. Singh, D.; Jain, N.; Jain, P.; Kayal, P.; Kumawat, S.; Batra, N. PlantDoc: A dataset for visual plant disease detection. In Proceedings of the 7th ACM IKDD CoDS and 25th COMAD, Hyderabad, India, 5-7 January 2020; pp. 249-253.

46. Yan, Q.; Yang, B.; Wang, W.; Wang, B.; Chen, P.; Zhang, J. Apple Leaf Diseases Recognition Based on an Improved Convolutional Neural Network. Sensors 2020, 20, 3535. [CrossRef]

47. Alruwaili, M.; Alanazi, S.; Abd, S.; Shehab, A. An Efficient Deep Learning Model for Olive Diseases Detection. Int. J. Adv. Comput. Sci. Appl. 2019, 10, 486-492. [CrossRef]

48. Vij, A.; Vijendra, S.; Jain, A.; Bajaj, S.; Bassi, A.; Sharma, A. IoT and Machine Learning Approaches for Automation of Farm Irrigation System. Procedia Comput. Sci. 2020, 167, 1250-1257. [CrossRef]

49. Mohanty, S.P.; Hughes, D.P.; Salathé, M. Using Deep Learning for Image-Based Plant Disease Detection. Front. Plant. Sci. 2016, 7, 1419. [CrossRef] [PubMed]

50. Cruz, A.C.; Luvisi, A.; De Bellis, L.; Ampatzidis, Y. X-FIDO: An Effective Application for Detecting Olive Quick Decline Syndrome with Deep Learning and Data Fusion. Front. Plant. Sci. 2017, 8, 1741. [CrossRef] [PubMed]

51. Rauf, H.T.; Saleem, B.A.; Lali, M.I.U.; Khan, M.A.; Sharif, M.; Bukhari, S.A.C. A citrus fruits and leaves dataset for detection and classification of citrus diseases through machine learning. Data Brief. 2019, 26, 104340. [CrossRef]

52. Kuaban, G.S.; Czekalski, P.; Molua, E.L.; Grochla, K. An Architectural Framework Proposal for IoT Driven Agriculture; Springer: Berlin, Germany, 2019; pp. 18-33.

53. Pathak, A.; Uddin, M.A.; Abedin, J.; Andersson, K.; Mustafa, R.; Hossain, M.S. IoT based Smart System to Support Agricultural Parameters: A Case Study. Procedia Comput. Sci. 2019, 155, 648-653. [CrossRef]

54. Thapa, R.; Snavely, N.; Belongie, S.; Khan, A. The plant pathology 2020 challenge dataset to classify foliar disease of apples. arXiv 2020, arXiv:2004.11958. 
55. Romeo, L.; Petitti, A.; Marani, R.; Milella, A. Internet of Robotic Things in Smart Domains: Applications and Challenges. Sensors 2020, 20, 3355. [CrossRef] [PubMed]

56. Sangeetha, S.K.B. Comparison of Crop Disease Detection Methods-An intensive analysis. Psychol. Educ. J. 2021, 58, 10540-10546. 